\title{
Asthma and Adherence to Inhaled Corticosteroids: Current Status and Future Perspectives
}

\author{
Camilla Boslev Bårnes MD and Charlotte Suppli Ulrik MD DMSc
}

\author{
Introduction \\ Methods \\ Review of the Literature \\ Adherence to ICS in Asthma: A Clinically Important Issue? \\ Does Better Adherence to ICS Improve Asthma Outcomes? \\ How Can We Improve Adherence to ICS? Which Interventions Work? \\ Summary and Perspectives
}

\begin{abstract}
Inhaled corticosteroids (ICS) are the cornerstone of maintenance asthma therapy. However, in spite of this, adherence to ICS remains low. The aim of this systematic literature review was to provide an overview of the current knowledge of adherence to ICS, effects of poor adherence, and means to improve adherence. A total of 19 studies met the inclusion criteria: 9 focusing on the level of adherence, 6 focusing on effects of poor adherence, and 7 focusing on interventions to improve adherence. Three of the studies focused on more than one of these end points. The mean level of adherence to ICS was found to be between 22 and $63 \%$, with improvement up to and after an exacerbation. Poor adherence was associated with youth, being African-American, having mild asthma, $<12 \mathrm{y}$ of formal education, and poor communication with the health-care provider, whereas improved adherence was associated with being prescribed fixed-combination therapy (ICS and long-acting $\beta_{2}$ agonists). Good adherence was associated with higher $\mathrm{FEV}_{1}$, a lower percentage of eosinophils in sputum, reduction in hospitalizations, less use of oral corticosteroids, and lower mortality rate. Overall, $24 \%$ of exacerbations and $60 \%$ of asthmarelated hospitalizations could be attributed to poor adherence. Most studies have reported an increase in adherence following focused interventions, followed by an improvement in quality of life, symptoms, $F V_{1}$, and oral corticosteroid use. However, 2 studies found no difference in health-care utilization, one observed no effect on symptoms, and one observed more symptoms in subjects in the intervention group compared with the control group. Good adherence to ICS in asthma improves outcome but remains low. Interventions to improve adherence show varying results, with most studies reporting an increase in adherence but unfortunately not necessarily an improvement in outcome. Even following successful interventions, adherence remains low. Further research is needed to explore barriers to adherence and interventions for improvement. Key words: asthma; adherence; controller medication; inhaled corticosteroids; asthma control; outcome. [Respir Care 2015;60(3):455-468. (C) 2015 Daedalus Enterprises]
\end{abstract} The authors are affiliated with the Department of Pulmonary Medi-
cine, Hvidovre Hospital, University of Copenhagen, Hvidovre, Den-
mark.

The authors have disclosed no conflicts of interests.
Correspondence: Charlotte Suppli Ulrik MD DMSc, Department of Pulmonary Medicine, Hvidovre Hospital, DK-2650 Hvidovre, Denmark. E-mail: csulrik@dadlnet.dk.

DOI: $10.4187 /$ respcare. 03200 


\section{Introduction}

Asthma is one of the most common chronic diseases, and it is estimated that $>300$ million people suffer from asthma worldwide, ${ }^{1}$ which has great impact on socioeconomics. Accordini et $\mathrm{al}^{2}$ have estimated the mean total cost of an asthma patient to be $\$ 1,583$ per year, comprising direct medical expenses, lost school days and workdays, and premature deaths. The prevalence of asthma varies between $7 \%$ in low-prevalence countries ${ }^{3}$ to $>15 \%$ in other western societies, where it seems to be increasing among adolescents. ${ }^{4}$

Inhaled corticosteroids (ICS) are the cornerstone of maintenance therapy for asthma. ${ }^{5}$ Multiple studies have shown ICS to improve symptoms and reduce asthma-related morbidity and mortality, ${ }^{6-8}$ but despite this, a high number of patients being treated according to guidelines remain difficult to control with frequent exacerbations and persisting symptoms. ${ }^{9}$ One of the plausible reasons for poorly controlled asthma may be that patients with asthma tend to exhibit poor adherence. ${ }^{10}$ Poor adherence to controller medication may lead to a decline in lung function, ${ }^{11}$ poor symptom control, ${ }^{12}$ and increased risk of asthma-related hospitalizations. ${ }^{13}$ Furthermore, poorly controlled asthma also places a much larger burden on the national economics compared with guideline-defined well-controlled asthma. ${ }^{2}$

The high percentage of patients not taking their ICS as prescribed also poses a challenge for health-care providers in identifying patients suffering from treatment-resistant or refractory asthma, which is generally defined as asthma not responding to high-dose therapy. ${ }^{9}$ This could lead to non-adherent patients being prescribed newer and often more expensive medications, which are reserved for patients with moderate-to-severe asthma who are uncontrolled on high-dose ICS and long-acting $\beta_{2}$ agonists, ${ }^{14}$ even though it is likely that they would have achieved comparable asthma control with optimal adherence to ICS instead.

The purpose of this review was to assess current knowledge on adherence to ICS in patients with asthma, focusing on the level of adherence, impact of poor adherence on symptoms and asthma outcomes, and possible effects of interventions aimed at improving adherence.

\section{Methods}

To perform this review, the general principles of the Preferred Reporting Items for Systematic Reviews and Meta-Analyses guidelines ${ }^{15,16}$ were adopted. A planned series of systematic searches were carried out (last updated April 2014) using the PubMed, Embase, Cochrane Central Register of Controlled Trials, and ClinicalTrials.gov databases with the following algorithm of MeSH terms: asthma, asthma-like symptoms AND adherence, compliance, con- troller medication, maintenance therapy, ICS. These searches were repeated with these terms in combination with lung function, $\mathrm{FEV}_{1}$, hospitalization, respiratory symptoms, nocturnal asthma, severe asthma, mortality, asthma control, systemic corticosteroids, induced sputum, and asthma exacerbation. All searches were limited to English-language publications. Studies were included if they met all the following criteria: (1) enrollment of adult subjects with asthma; (2) assessment of at least one of the following outcome variables: level of adherence in asthma, effects of poor adherence on asthma outcomes, and possible effects of specific interventions; and (3) exclusion of patients with COPD, concomitant heart disease, or other serious chronic diseases. As the methods and results could not be fully assessed, clinical trials published only in abstract form were excluded from this review. Primarily due to the relatively limited number of published clinical trials fulfilling all inclusion criteria, a meta-analysis was not included in this review.

\section{Review of the Literature}

A total of 19 studies, comprising 26,563 subjects, fulfilled the inclusion criteria and were included in this review. Of these 19 studies, 9 studies assessed the level of adherence to ICS, 6 studies assessed the effects of poor adherence on asthma outcomes, and 7 studies focused on the possible effects of interventions aimed at improving adherence. Three of the studies focused on more than one of these end points.

\section{Adherence to ICS in Asthma: A Clinically Important Issue?}

Williams et al ${ }^{17}$ conducted a study based on 1,064 subjects with a doctor's diagnosis of asthma and at least one electronic prescription for ICS over an 18-month period (Table 1). Adherence was calculated as the total number of days of supplied medicine divided by the number of days of observation (continuous multiple-interval measure of medication availability [CMA]) by linking the electronic prescriptions with the prescription fill information. The number of days a canister would last was calculated by dividing the canister size (the number of puffs) by the prescribed number of puffs/d. In order not to underestimate or overestimate adherence, a minimum of 3 months of follow-up was required, giving a denominator $\geq 90 \mathrm{~d}$. To account for pre-existing medication surplus, the previous 3 months' ICS prescription fills were examined, and the index date was moved back accordingly when a possible surplus was found. On average, adherence in the entire population was $46 \%$. However, $8 \%$ of the cohort never filled the prescriptions and was therefore classified as being non-adherent. Based on the level of adherence, 


\section{Asthma And AdHerence to InHaled Corticosteroids}

Table 1. Studies Investigating the Level of Adherence to ICS in Adults With Asthma

\begin{tabular}{|c|c|c|c|c|}
\hline Study & $\begin{array}{l}\text { Subjects } \\
\quad(n)\end{array}$ & $\begin{array}{l}\text { Adherence } \\
\text { Measure }\end{array}$ & $\begin{array}{c}\text { Average } \\
\text { Adherence }(\%)\end{array}$ & Other Findings \\
\hline Williams et al ${ }^{17}$ & 1,064 & CMA & 46 & $\begin{array}{l}\text { Poor adherence was associated with being young and African-American and having } \\
\text { milder asthma. }\end{array}$ \\
\hline Williams et al ${ }^{18}$ & 298 & CMA & 26 & Adherence improved in the time up to and after exacerbations. \\
\hline Williams et al ${ }^{19}$ & 176 & CMA & 50 & \\
\hline Murphy et al 20 & 115 & CMA & & $\begin{array}{l}\text { Adherence of }<80 \% \text { was found in } 65 \% \text { of subjects. Adherence was better in } \\
\text { subjects prescribed fixed-combination therapy (ICS and long-acting } \beta_{2} \text { agonists) } \\
\text { compared with combination therapy (ICS and long-acting } \beta_{2} \text { agonists prescribed } \\
\text { in separate inhalers). }\end{array}$ \\
\hline Gamble et $\mathrm{al}^{21}$ & 182 & CMA & & $\begin{array}{l}\text { Adherence of }<50 \% \text { was found in } 35 \% \text { of subjects, with } 12 \% \text { continuing to claim } \\
\text { good adherence despite evidence of non-adherence. }\end{array}$ \\
\hline Bender et $\mathrm{al}^{22}$ & 5,504 & CMA & 22 & $\begin{array}{l}\text { The highest observed adherence was } 26 \% \text {, and only } 8.8 \% \text { of subjects persisted with } \\
\text { ICS throughout } 1 \mathrm{y} \text {. }\end{array}$ \\
\hline Hwang et $\mathrm{al}^{23}$ & 108 & MPR & & Adherence was $>75 \%$ in $23 \%$ of subjects. \\
\hline Ulrik et al ${ }^{24}$ & 509 & & & $\begin{array}{l}\text { A total of } 67 \% \text { subjects were prescribed ICS, although } 86 \% \text { should have been } \\
\text { prescribed ICS based on asthma severity; } 68 \% \text { changed their ICS dose without } \\
\text { contacting their general practitioner. }\end{array}$ \\
\hline Apter et al25 & 50 & MDI & 63 & $\begin{array}{l}\text { Poor adherence was associated with poor communication with the health-care } \\
\text { provider and }<12 \text { y of formal education. }\end{array}$ \\
\hline \multicolumn{5}{|c|}{$\begin{array}{l}\text { ICS }=\text { inhaled corticosteroids } \\
\text { CMA }=\text { continuous multiple-interval measure of medication availability } \\
\text { MPR }=\text { medical possession ratio } \\
\text { MDI = metered-dose inhaler }\end{array}$} \\
\hline
\end{tabular}

the remaining subjects were classified as either poor-tomoderate adherent (adherence of $<80 \%$ ) or adherent (adherence of $>80 \%$ ). Subjects classified as being nonadherent or poor-to-moderately adherent were more likely to be young and African-American. However, these subjects also had lower comorbidity scores and less use of short-acting $\beta_{2}$ agonists and oral corticosteroids in the previous year, suggesting that these subjects may have milder asthma compared with the more adherent subjects. Surprisingly, however, Williams et al ${ }^{17}$ found no difference between these groups with regard to number of visits to out-patient clinics or, more interestingly, number of emergency room visits or hospitalizations.

In 2 additional studies, Williams et al ${ }^{18,19}$ also reported an average adherence to ICS at or below 50\% (see Table $1)$. In the first of these studies, ${ }^{18}$ they calculated CMA prior to and following the index health-care contact to assess changes in adherence before and after an exacerbation. An exacerbation was defined as a visit to the emergency room, hospitalization, or a rescue course of oral steroid, and the participants were recruited from the Study of Asthma Phenotypes and Pharmacogenomic Interactions by Race-Ethnicity (SAPPHIRE). The authors reported a change in adherence from $19 \%$ in the $60 \mathrm{~d}$ before an exacerbation to $32 \%$ in the $160 \mathrm{~d}$ after.

In the second of these studies, Williams et al ${ }^{19}$ calculated the CMA for 176 asthma subjects enrolled in large health-maintenance organizations for at least $2 \mathrm{y}$ after the index year (see Table 1). The CMA was found to be
$50 \pm 37 \%$ (mean \pm SD). Furthermore, the authors also estimated the continuous multiple-interval measure of medication gaps (CMG) as the total number of days of treatment gaps divided by the total number of days between refills during the observation period to $54 \pm 27 \%$. CMA and CMG were calculated based on the first and last ICS prescription fills during the study period, with a requirement of a 2-fill minimum in that period.

Murphy et $\mathrm{al}^{20}$ studied the level of adherence to ICS in 115 subjects regularly attending a specialized difficult asthma clinic (see Table 1). Adherence was calculated as CMA based on prescription data from their general practitioners and the hospital's dispensing system. Suboptimal adherence ( $<80 \%$ of the medication taken) was found in $65.2 \%$ of the total population. Of the subjects prescribed fixed-combination therapy with ICS and long-acting $\beta_{2}$ agonists, $62.4 \%$ had poor adherence, whereas $85.7 \%$ of the subjects prescribed ICS and long-acting $\beta_{2}$-agonists in separate inhalers had adherence of $<80 \%$. In the latter group, adherence to long-acting $\beta_{2}$ agonists was much better (50\%) than to ICS $(14.3 \%)$. Therefore, these findings strongly suggest that patients with asthma requiring treatment with a combination of ICS and long-acting $\beta_{2}$ agonists should be prescribed fixed-combination therapy.

Gamble et al ${ }^{21}$ investigated adherence to ICS in 182 subjects also referred to a specialized clinic for difficult asthma (see Table 1). Thirty-five percent of the subjects filled $\leq 50 \%$ of their ICS prescriptions. Women were significantly more likely to be non-adherent than men. When 
subjects were confronted with the evidence for non-adherence, $88 \%$ admitted not using their ICS as prescribed, whereas the remaining $12 \%$ continued to claim good adherence despite the prescription records.

Bender et $\mathrm{al}^{22}$ studied filled ICS prescriptions for $1 \mathrm{y}$ in 5,504 subjects with asthma and reported an average adherence to fixed-combination therapy with salmeterol/fluticasone of $22.2 \%$ (see Table 1). Furthermore, more than half of the subjects $(58.9 \%)$ filled their prescriptions only once in the 12-month study period. Men were slightly more adherent than women ( $23 \%$ vs $21 \%)$, whereas younger subjects had poorer adherence than older subjects $(<20 \%$ adherence in the 12-35-y-old group and $>20 \%$ adherence in the $>35$-y-old group). The highest adherence was observed in subjects $>70$ y of age, although it was only $26 \%$. Other factors associated with poor adherence were low-dose ICS and lower medication costs. The former finding is probably because subjects prescribed higher doses of ICS experienced more symptoms and thus were more likely to fill their prescriptions. Furthermore, Bender et $\mathrm{al}^{22}$ also studied persistence with ICS, defined as the percentage of subjects who continued filling their prescriptions throughout the year. They found that only $8.8 \%$ of the subjects persisted with their controller therapy, and low persistence was associated with gender (women had a 9.2\% higher risk of discontinuation compared with men, $P=.002$ ) and age (subjects $<55$ y of age were more likely to discontinue treatment than those $>70 \mathrm{y}$ of age, $P<.001)$.

Hwang et al ${ }^{23}$ studied 108 subjects $>60$ y of age with a diagnosis of asthma (see Table 1). The enrolled subjects were grouped according to their asthma control, as defined by the Asthma Control Test, into group I with a score of $<19$ (poor control) and group II with a score of $>19$ (good control). Adherence of $>75 \%$ was observed in $29 \%$ of subjects in group I and 20\% in group II. Average adherence for all included subjects was $23 \%$.

Ulrik et al ${ }^{24}$ performed a cross-sectional study of 509 adults with asthma, all members of an internet-based panel (see Table 1). The subjects filled out a 41-item questionnaire regarding their knowledge of asthma, disease monitoring, treatment, adherence, and attitudes toward treatment, both in general and with specified treatment options. Based on their symptoms, a total of $86 \%$ of the subjects met the criteria for having ICS prescribed as preventive therapy, but only $67 \%$ were prescribed ICS. The subjects' knowledge of asthma was good in general, with a large proportion of subjects understanding that asthma is a chronic inflammatory disease, varying over time, and that, as recommended in guidelines at the time of the study, controller medication should be increased with increasing symptoms and increased need for reliever medication. Overall, 68\% adjusted (ie, increased or reduced) their ICS dose without prior contact with their physician, and $>50 \%$ decreased their ICS dose when experiencing fewer symptoms. Although 59\% knew that they were supposed to increase their ICS dose when experiencing worsening of asthma symptoms, only $23 \%$ did so. No association was found between self-believed disease severity and response to an episode of worsening symptoms.

Apter et $\mathrm{al}^{25}$ assessed possible factors contributing to poor ICS adherence (see Table 1). The adherence of a total of 50 adults with moderate-to-severe asthma was monitored for $42 \mathrm{~d}$ using a metered-dose inhaler, which recorded every actuation of the inhaler. Only the data from the last 5 weeks were used to rule out any enrollment effect in the first week. Prior to the test period, subjects filled out questionnaires on lifetime number of hospitalizations for asthma, admittance to an ICU for asthma, number of sick-leave days due to asthma in $1 \mathrm{y}$, symptoms, and use of oral steroids 6 months prior to enrollment. After the study period, the subjects' knowledge of asthma pathophysiology and asthma medication effects was assessed, as well as their thoughts on controller medication effects and convenience and their perception of the level of communication with their physician. Average adherence to ICS was $63 \%$, and $54 \%$ of the subjects had an adherence of $>70 \%$ with the prescribed dose of ICS. In a multivariate analysis, the only factors individually contributing to poor adherence were $<12$ y of formal education (odds ratio of 6.72) and poor communication with the physician, assessed by a questionnaire developed for this purpose (odds ratio of 1.2). The authors also described different patterns of non-adherence, corresponding to the subjects' beliefs about the effects and convenience of ICS. Some subjects took the prescribed dose with each use but forgot to use the medication as often as prescribed, whereas others took a lower dose than prescribed and less often than prescribed. Some subjects also used a higher dose than prescribed at some point.

In summary, the 9 studies reviewed in this section all showed adherence to ICS to be less than optimal, ranging from 22 to $63 \%$. Factors associated with poor adherence were youth, being African-American, having milder asthma, $<12$ y of formal education, and inadequate communication with the health-care provider. Furthermore, these studies also revealed that poor adherence presented in several forms, including use of lower doses than prescribed and less persistence with the prescribed controller medication. Therefore, these studies clearly show that adherence to controller medication is a major and clinically important issue in asthma management.

\section{Does Better Adherence to ICS Improve Asthma Outcomes?}

In the study mentioned above by Murphy et al, ${ }^{20}$ subjects with adherence of $>80 \%$ had a significantly higher 


\section{Asthma And AdHerence to InHaled Corticosteroids}

Table 2. Studies Investigating the Association Between Adherence to ICS and Asthma-Related Outcomes

\begin{tabular}{|c|c|c|}
\hline Study & $\begin{array}{c}\text { Subjects } \\
(n)\end{array}$ & Results \\
\hline Williams et $\mathrm{al}^{18}$ & 298 & $\begin{array}{l}\text { A } 25 \% \text { increase in adherence resulted in } 11 \% \text { less risk of a negative outcome, and } 24 \% \text { of all } \\
\text { exacerbations could have been avoided by optimal adherence. }\end{array}$ \\
\hline Williams et al ${ }^{19}$ & 176 & $\begin{array}{l}\text { CMA was negatively associated with poor asthma outcome. A } 25 \% \text { increase in CMA gave a } 25 \% \\
\text { reduction in the number of rescue courses of oral corticosteroids. Of all asthma hospitalizations, } 60 \% \\
\text { could be attributed to non-optimal ICS adherence. }\end{array}$ \\
\hline Murphy et al20 & 115 & $\begin{array}{l}\text { Subjects with adherence of }>80 \% \text { had higher } \mathrm{FEV}_{1} \text { and lower percentage of sputum eosinophils. No } \\
\text { difference was found regarding symptoms or exacerbations. }\end{array}$ \\
\hline Suissa et $\mathrm{al}^{26}$ & 3,894 & $\begin{array}{l}\text { Regular ICS use was associated with a } 31 \% \text { reduction in hospitalizations and a } 39 \% \text { reduction in re- } \\
\text { hospitalizations. }\end{array}$ \\
\hline Suissa et $\mathrm{al}^{27}$ & 2,747 & $\begin{array}{l}\text { The rate of death from asthma in ICS users decreased by } 54 \% \text { for each additional canister used in the } \\
6 \text { mo prior to the index date. The death rate was higher in the } 3 \text { mo after discontinuing ICS. }\end{array}$ \\
\hline Bateman et $\mathrm{al}^{28}$ & 1,058 & Achieving guideline-based asthma control was associated with near-optimal quality of life. \\
\hline
\end{tabular}

percent-predicted $\mathrm{FEV}_{1}$ and lower percentage of sputum eosinophils compared with subjects with a lower level of adherence (Table 2). No difference was found with regard to symptoms (assessed by the Asthma Control Questionnaire $[\mathrm{ACQ}]^{29}$ ), hyperventilation (assessed by the Nijmegen questionnaire ${ }^{30}$ ), or anxiety and depression (assessed by the Hospital Anxiety and Depression Scale ${ }^{31}$ ). Furthermore, when looking at the previous year, they found no significant differences in the number of rescue courses of oral corticosteroids or hospital or ICU admissions due to a severe asthma exacerbation. However, they observed that poor adherence was an independent predictor of a previous episode of mechanical ventilation due to severe asthma.

From 1999 to 2001, Williams et al ${ }^{19}$ calculated CMA and CMG for 176 subjects with asthma and assessed the potential negative outcomes associated with poor adherence (see Table 2). The outcomes of interest were courses of oral corticosteroids, asthma-related contacts with an out-patient clinic or emergency department, and asthmarelated hospitalization within a $2-y$ follow-up period. To calculate adherence, a minimum of 2 prescriptions had to be filled during the study period. Patients with $<2$ filled prescriptions were excluded from the analyses, but the available information suggested that these patients had milder asthma, as indicated by lower use of oral corticosteroids and rescue short-acting $\beta_{2}$ agonists and fewer asthma-related hospitalizations. Among the 176 subjects included, the mean CMA was $50 \%$, and the mean CMG was $54 \%$. CMA was negatively associated and CMG was positively associated with poor asthma outcomes. Both CMA and CMG significantly correlated with use of oral corticosteroids (both number of filled prescriptions and total days prescribed), asthma-related hospitalizations, and asthma-related visits to an emergency department. Based on their findings, the authors suggested that CMG may be a slightly better indicator of the association between adherence and negative asthma outcomes compared with CMA. After adjusting for age, gender, ethnicity, and number of filled prescriptions for short-acting $\beta_{2}$ agonists and ICS (as a measure of asthma severity), a $25 \%$ increase in CMG was found to double the risk of asthma-related hospitalizations (relative risk of 2.01). Lastly, their study revealed that a $25 \%$ increase in CMA gave a $25 \%$ reduction in the number of filled prescriptions for oral corticosteroids. On the basis of their observations, Williams et al ${ }^{18}$ concluded that $60 \%$ of all asthma-related hospitalizations could be attributed to non-optimal ICS adherence and, furthermore, that it is not only total use of ICS that is important but also continuous use of ICS.

Asthma is known to be a fluctuating disease, with periods of fewer symptoms as well as periods with worsening symptoms and, in some cases, exacerbations. Williams et al ${ }^{18}$ therefore hypothesized that adherence to ICS likewise would be changing over time. They investigated changes in ICS adherence and how adherence relates to asthma exacerbations, defined as asthma-related hospitalizations, contact with an emergency room, or rescue course of oral corticosteroids. The enrolled subjects were part of the SAPPHIRE study, as described by Jin et al. ${ }^{32}$ All subjects had a diagnosis of asthma, medical and pharmacy coverage, and a minimum of one ICS prescription filled during the study period. Patients were excluded if they had congestive heart failure or COPD. A total of 298 subjects were enrolled in the study, and mean adherence at baseline was $26 \%$. The study revealed an improvement in adherence up to and after the first exacerbation. Although this could be interpreted as a positive association between good adherence and exacerbations, further analyses, after adjusting for asthma severity (including use of rescue shortacting $\beta_{2}$ agonists, level of $\mathrm{FEV}_{1}$, and bronchodilator re- 


\section{Asthma And AdHerence to InHaled Corticosteroids}

versibility) and prior exacerbations (rescue courses of oral steroids, emergency room visits, and hospitalizations), revealed that good adherence had a protective effect on exacerbations. In fact, every $25 \%$ increase in adherence gave $11 \%$ less risk of having one of the negative asthma-related outcomes. However, after dividing the subjects into groups based on asthma control at baseline and level of adherence, Williams et al ${ }^{18}$ found the effects to be statistically significant only in the group with poor initial asthma control and in subjects with $>75 \%$ adherence to ICS. Overall, the authors found that $24 \%$ of all asthma exacerbations in the study could have been avoided with optimal ICS adherence.

In 2002, Suissa et al ${ }^{26}$ studied a Canadian cohort comprising 30,569 subjects 5-44 y of age, with at least 3 ICS prescriptions during a 16-y period (see Table 2). All enrolled subjects were followed from their first ICS prescription to their 55th birthday, death, moving to another province, end of health-care coverage, or December 31, 1997, whichever came first. The minimum duration of follow-up was $1 \mathrm{y}$, and data were analyzed for 2 groups: all subjects and subjects who were admitted to a hospital during the first year after their first prescription. The index date was $365 \mathrm{~d}$ after being enrolled in the study or after the first hospitalization, and the index year was the year preceding the index date. In the first group (full cohort), there were 3,894 subjects who had been admitted to a hospital, giving an overall hospitalization rate of 42 per 1,000 asthma subjects per year. In the second group $(n=5,894$, subjects with a hospitalization in the first year of follow-up), 1,886 subjects were readmitted at some point during follow-up, giving a total readmission rate of 153 per 1,000 asthma subjects per year. The assessment of adherence to ICS was based on prescriptions in the index year. The subjects were divided into 2 groups: regular ICS use (minimum of one ICS canister filled each quarter of that year) and irregular ICS use (any other pattern of filled prescriptions). The study showed that regular use of ICS was associated with a $31 \%$ reduction in asthma-related admission to hospitals in the entire cohort and a 39\% reduction in the second cohort compared with irregular use.

In the same cohort, Suissa et $\mathrm{al}^{27}$ also investigated asthma-related deaths (see Table 2). Every death in a total cohort of 30,569 subjects was assessed individually by 2 pulmonary physicians, who reviewed all death certificates to identify deaths caused by asthma. The subjects who were determined by both physicians to have died from asthma were each matched with all controls from the cohort who met pre-specified criteria (eg, time of entry, follow-up time, previous hospitalizations, and use of rescue short-acting $\beta_{2}$ agonists and oral corticosteroids). Adherence to ICS was determined based on the total number of canisters dispensed 12 months before and 6 months after the index date. Regular ICS users were defined as de- scribed above, whereas irregular users were divided into 3 groups based on whether they discontinued ICS 3,6 , or 9 months prior to the index date. To determine a possible dose-response effect, the subjects were stratified into 3 groups: no ICS use, use of less than half a canister per month, and use of half a canister or more per month. Of the 562 deaths in the cohort, 77 were classified as being caused by asthma. Eleven cases were excluded for various reasons, leaving 66 cases matched with 2,681 controls in the final cohort. All subjects in the final cohort were classified as having severe asthma. Use of half a canister or more per month gave an adjusted rate ratio of 0.15 for asthma-related death. Based on the dose-response analysis, the rate of death from asthma in ICS users decreased by $21 \%$ for each additional canister used in the year prior to the index date and by $54 \%$ for each additional canister used in the 6 months prior to the index date. Finally, the study also revealed a significant higher rate of death in the 3 months after discontinuing ICS, with similar although not statistically significant findings for longer periods of discontinued use.

In the Gaining Optimal Asthma Control (GOAL) study, Bateman et $\mathrm{al}^{28}$ showed that with step-up therapy, it is possible in the majority of cases to achieve guidelinedefined good asthma control (see Table 2). They wondered, however, if achieving the guideline-defined treatment goal correlated with a subjective improvement in the patients' quality of life, and therefore, they performed a retrospective analysis of 3 studies with a total of 1,058 subjects. ${ }^{33}$ Asthma control based on the Global Initiative for Asthma (GINA) guidelines was assessed by looking at subjects' diary cards (symptoms, use of $\beta_{2}$ agonists, morning peak expiratory flow $[\mathrm{PEF}]$ ) and case record forms (hospitalizations, reported adverse effects). The subjects were classified as well controlled or not well controlled based on the findings 5-12 weeks after randomization. Quality of life was assessed with the Asthma Quality of Life Questionnaire (AQLQ), with an overall score of 7 meaning no impairment in quality of life due to asthma. Subjects achieving asthma control according to guidelines scored higher on the AQLQ than the subjects who were not well controlled. Regardless of the treatment intervention, the AQLQ score averaged 6 or higher in the wellcontrolled group, except for one group in one of the studies. With regard to improved quality of life (not the total AQLQ score), the group that significantly improved scores $(>0.5)$ had a higher proportion of subjects who achieved good asthma control compared with the group with an AQLQ score improvement of $<0.5$. Bateman et al ${ }^{5,28}$ concluded that improving patient asthma control as recommended in the GINA guidelines 5 is associated with a nearoptimal quality of life for the majority of well-controlled patients. 


\section{Asthma And AdHerence to InHALEd Corticosteroids}

Table 3. Studies Investigating the Effects of Interventions Aimed at Improving Adherence to ICS in Adults With Asthma and the Effect on Asthma Outcomes

\begin{tabular}{|c|c|c|c|}
\hline Study & $\begin{array}{l}\text { Subjects } \\
\quad(n)\end{array}$ & Intervention & Results \\
\hline Rasmussen et al ${ }^{34}$ & 300 & $\begin{array}{l}\text { Internet-based management tool vs general } \\
\text { practitioner or specialist out-patient } \\
\text { clinic care }\end{array}$ & $\begin{array}{l}\text { Greater improvement in lung function, symptoms, and } \\
\text { quality of life was observed in the intervention group. } \\
\text { All groups had an increase in adherence, with } \\
\text { significantly more in the intervention and specialist } \\
\text { groups. }\end{array}$ \\
\hline Araújo et al ${ }^{35}$ & 21 & $\begin{array}{l}\text { Web-based vs paper-based self- } \\
\text { management strategies }\end{array}$ & $\begin{array}{l}\text { Significant improvement in quality of life was observed } \\
\text { in both groups, with no improvement in other } \\
\text { outcomes, apart from a reduction in } \mathrm{F}_{\mathrm{ENO}} \text { in the web- } \\
\text { based intervention group. A total of } 57 \% \text { of the } \\
\text { subjects in the web-based group wanted to continue } \\
\text { using the web-based tool. }\end{array}$ \\
\hline Vollmer et $\mathrm{al}^{36}$ & 8,517 & Interactive voice recognition calls & $\begin{array}{l}\text { A significant increase in adherence in the intervention } \\
\text { group was observed. Of the subjects in the } \\
\text { intervention group, } 50 \% \text { wanted to continue receiving } \\
\text { calls, and 33\% felt their asthma was better controlled } \\
\text { due to the calls. }\end{array}$ \\
\hline Wilson et $\mathrm{al}^{37}$ & 612 & $\begin{array}{l}\text { Shared decision-making vs clinician } \\
\text { decision-making }\end{array}$ & $\begin{array}{l}\text { Significantly higher CMA at the 1-y follow-up was } \\
\text { observed in the shared decision-making group. No } \\
\text { difference in quality of life was found between } \\
\text { groups, but a higher percentage of subjects in the } \\
\text { shared decision-making group had an increase of } \\
>0.5 \text { in the mini-AQLQ. No difference in health- } \\
\text { care utilizations was found between groups. }\end{array}$ \\
\hline Clark et al ${ }^{38}$ & 808 & $\begin{array}{l}\text { Asthma care plan developed together with } \\
\text { physician }\end{array}$ & $\begin{array}{l}\text { Subjects with negotiated plans had an odds ratio of } 2.4 \\
\text { for ICS adherence usually or sometimes and had } 17 \% \\
\text { more days and } 31 \% \text { more nights without symptoms } \\
\text { than those without a plan. No differences in contacts } \\
\text { with hospitals or general practitioners were found. }\end{array}$ \\
\hline Gamble et $\mathrm{al}^{39}$ & 239 & $\begin{array}{l}\text { Up to } 8 \text { educational and motivational visits } \\
\text { with a specialist nurse }\end{array}$ & $\begin{array}{l}\text { Adherence improved in the intervention group and } \\
\text { decreased in the control group. The control group had } \\
\text { an increase in use of maintenance oral prednisolone } \\
\text { compared with a reduction in the intervention group. }\end{array}$ \\
\hline Ulrik et al ${ }^{40}$ & 361 & $\begin{array}{l}\text { Three } \sim 60 \text {-min compliance enhancement } \\
\text { training sessions }\end{array}$ & $\begin{array}{l}\text { Over } 90 \% \text { of the subjects attended each session. No } \\
\text { significant difference was found in asthma control } \\
\text { achieved, days with symptoms, or use of rescue } \\
\text { medication. }\end{array}$ \\
\hline \multicolumn{4}{|c|}{$\begin{array}{l}\text { ICS }=\text { inhaled corticosteroids } \\
\mathrm{F}_{\mathrm{ENO}}=\text { fraction of exhaled nitric oxide } \\
\mathrm{CMA}=\text { continuous multiple-interval measure of medication availability } \\
\mathrm{AQLQ}=\text { Asthma Quality of Life Questionnaire }\end{array}$} \\
\hline
\end{tabular}

In all 6 studies reviewed in this section, it was determined that good adherence to ICS was beneficial for subjects with asthma. One study showed an improvement in $\mathrm{FEV}_{1}$ and a lower percentage of eosinophils in sputum, although no significant subjective effects were found. The other studies found that good adherence to ICS had a positive impact on asthma-related mortality and the number of courses of oral steroids and, furthermore, that $24 \%$ of asthma exacerbations and $60 \%$ of asthma-related hospitalizations could be attributed to poor adherence to ICS. This clearly indicates that good adherence to ICS improves asthma-related outcomes, a fact that should be properly emphasized to both patients and health-care providers involved in asthma management.

\section{How Can We Improve Adherence to ICS? Which Interventions Work?}

In a study from Denmark, Rasmussen et al ${ }^{34}$ investigated the effect of an internet-based management tool on asthma outcomes (Table 3). A total of 300 subjects with asthma, as defined by the American College of Allergy, Asthma and Immunology asthma questionnaire, ${ }^{41}$ were recruited. The subjects were randomized to standard asthma 


\section{Asthma And AdHerence to InHaled Corticosteroids}

care by their general practitioner, treatment by specialists in pulmonary medicine in an out-patient clinic, or specialist treatment through an internet-based management tool. At the time of enrollment and at the end of the 6-month trial period, all subjects had scheduled appointments at the out-patient clinic for clinical interview, questionnaires, bronchial challenge testing (methacholine), and spirometry. Subjects randomized to the general practitioner group were asked to provide their general practitioner with the test results obtained prior to randomization, and for the remaining part of the study period, these subjects were managed solely by their general practitioner, and no additional information or treatment advice was provided by secondary care. In the specialist group, subjects were treated according to the severity of their asthma. They were given a written action plan with a 3-color system based on PEF and symptoms, and they were taught how to adjust their treatment according to symptoms and PEF measurements. In the internet group, subjects were instructed to fill out electronic diary cards with symptoms, PEF, and use of rescue short-acting $\beta_{2}$ agonists, and the internet management tool then gave the subjects a written treatment plan based on the same 3-color system as in the specialist group. During the study period, 47 subjects dropped out, evenly distributed among the groups. Baseline characteristics revealed no significant differences between groups. At follow-up, there was a significantly better improvement in lung function, symptom scores, and quality of life in the internet group compared with the other 2 groups, whereas no significant difference was found between the specialist out-patient care and the general practitioner groups. ICS use was reported by the subjects and was not measured objectively. At baseline, 51\% of the subjects did not take any medication for their asthma. All groups showed an increase in ICS use at follow-up, but significantly more subjects in the specialist and internet groups used ICS at follow-up. The internet, specialist, and general practitioner groups provided self-reported good adherence (taking the ICS always/almost always) rates of 87,79 , and $54 \%$, respectively.

Araújo et al ${ }^{35}$ compared a web-based and a paper-based self-management strategy in terms of feasibility, safety, and clinical efficacy (see Table 3). A total of 21 adults (19 completed the study) with moderate-to-severe asthma who were prescribed ICS and had an $\mathrm{FEV}_{1}$ of $>50 \%$ of predicted were randomized to a treatment sequence consisting of two 4-week periods with each intervention. Quality of life and asthma control were assessed before and after each intervention using the AQLQ, mini-AQLQ, and ACQ-5. A physical examination, spirometry, and measurements of the fraction of exhaled nitric oxide $\left(\mathrm{F}_{\mathrm{ENO}}\right)$ were also included. No differences in baseline characteristics were observed between groups. Subjects were instructed in how to use the monitoring instruments, the web-based application, and the paper-based diary and action plan and to fill in the relevant information once daily, just before taking their ICS. In the web-based strategy Portal for Assessment and Self-Management of Asthma, the subjects recorded $\mathrm{FEV}_{1}$, PEF, symptoms, and exacerbations and received immediate graphic and written feedback based on their personal action plan designed by their physician. In the paper-based strategy, the subjects filled out asthma diary cards and had a written action plan similar to the one in the internet application. No significant differences in clinical outcomes $\left(\mathrm{FEV}_{1}, \mathrm{PEF}, \mathrm{AQLQ}, \mathrm{ACQ}\right.$, and $\mathrm{F}_{\mathrm{ENO}}$ ) were found between the 2 interventions. Both groups had a significant improvement as assessed by the AQLQ and ACQ, whereas no significant improvement in lung function was observed. A significant reduction in $\mathrm{F}_{\mathrm{ENO}}$ was seen following the internet-based intervention only, from 49 parts/billion at baseline to 33 parts/billion at post-internet intervention, corresponding to a $32 \%$ reduction that, according to Dweik et al, ${ }^{42}$ indicates a significant response to anti-inflammatory treatment. Adherence to the paper-based strategy was significantly greater compared with the internet-based strategy, but adherence in the 2 groups was comparable with regard to lung function monitoring as well as time used for disease monitoring. Subjects' preferences and opinions regarding the monitoring tools were also assessed based on open-ended questions, questionnaires, and short interviews. Two subjects gave negative ratings to the web-based tool, and 11 subjects gave negative ratings to the paper-based system; 12 subjects $(57 \%)$ were very interested in continuing use of the web-based system, and 2 wanted to keep using the paperbased monitoring. The small number of subjects enrolled in this study makes it difficult to draw valid conclusions with regard to the clinical efficacy of this intervention.

Vollmer et $\mathrm{al}^{36}$ also studied the effects of health information technology on adherence to controller medication in subjects with asthma (see Table 3). A total of 8,517 subjects were randomized to receive either usual standard care or interactive voice recognition (IVR) calls. The IVR consisted of 3 types of calls: the refill reminder call, the tardy refill call, and the initiator/restart call. Each month, the electronic medical records were scanned to identify subjects who qualified for an IVR call. Those with less than 1 month's supply left (last refill $>1$ month ago) received a refill reminder call. If subjects were $>1$ month past their refill date, they received a tardy refill call, reminding them to refill their ICS and assessing asthma control, barriers to ICS adherence, and also tailored educational messages. The initiator/restart call went to those with an ICS prescription fill in the last month and no records of other ICS refills the previous 6 months, as the subjects were regarded as new or relapsed users of ICS. These calls were similar to the tardy refill calls in including questions about control, barriers to adherence, and 
education. Adherence was calculated as the medical possession ratio (ie, number of days of supplied medicine divided by number of days in the study period). At baseline and follow-up, subjects filled in the mini-AQLQ. The follow-up survey also included the Asthma Therapy Assessment Questionnaire, as well as questions about satisfaction with the intervention. From the electronic medical records, data on age, gender, smoking, concomitant COPD, acute asthma health-care utilizations, and use of oral steroids and rescue short-acting $\beta_{2}$ agonists were also obtained. The 2 groups were very similar at baseline, and both groups had a mean medical possession ratio of $42 \%$. A total of 3,171 subjects were included in the intervention group, and they received a total of 11,714 IVR calls: $27 \%$ were refill reminder calls, $61 \%$ were tardy refill calls, and the last $12 \%$ were initiator/restart calls. In the intervention group, $91 \%$ of the subjects received at least one tardy refill call, and 55\% received 2 or more direct contacts or detailed messages. A total of $84 \%$ of all calls resulted in some kind of detailed message. In the primary analysis, a small but significant increase in adherence was found in the intervention group compared with the usual-care group. When limiting the analyses to the $55 \%$ of the subjects who received at least 2 detailed messages, the effect of the intervention on adherence was 3 times greater. A significant improvement in the proportion of subjects with good control was also found, but surprisingly, at the same time, also a significant increase in health-care utilizations. Of the subjects, 50\% reported that they found the IVR calls useful and would like to continue to have these calls, and $33 \%$ felt that their asthma was better controlled due to the calls.

Wilson et $\mathrm{al}^{37}$ investigated the efficacy of more patient involvement in the decision making regarding disease management (see Table 3). A total of 612 adults with poorly controlled asthma (defined by use of rescue medication or a recent asthma-related hospitalization or emergency department visit) were randomized to either shared decision making or clinician decision making. The interventions were identical in the 2 groups; only the process of decision making was different. In the clinician decision-making group, the clinician decided on a treatment regimen depending on the level of asthma control. In the shared decision-making group, the clinician explored the patient's goals and priorities about treatment, side effects, symptom control, and treatment costs. The patient and the clinician then together evaluated the pros and cons of all guidelinebased treatment options and decided on the optimal treatment plan. Both groups received asthma education, 2 personal sessions (at 0 and +1 month) and 3 telephone encounters (at $+3,6$, and 9 months), as well as a written management and action plan. CMA was calculated for $1 \mathrm{y}$ pre-randomization and $2 \mathrm{y}$ post-randomization. The primary clinical outcomes were quality of life (mini-AQLQ) and asthma-related health-care utilization (emergency department visits, out-patient contacts, and hospitalizations for $1 \mathrm{y}$ pre-randomization and $1 \mathrm{y}$ post-randomization). Secondary clinical outcomes were lung function and asthma control (Asthma Therapy Assessment Questionnaire) at baseline and at the 1-y follow-up. In the shared decisionmaking group compared with the clinician decision-making group, the initial session was 29 min longer on average, and each telephone contact lasted 5 min longer, whereas no difference was found with regard to the second session. The difference in costs between the groups was estimated to be $\$ 32$ (based on an average care-manager salary). No difference was found between the groups at baseline, but at the 1-y follow-up, the subjects with influence on the decision making had a significantly higher CMA (67\%) compared with subjects not involved in the process (59\%). However, at the 2-y follow-up, the CMA remained higher than at baseline, but with no significant difference between groups. No significant difference in quality of life was found at the 1-y follow-up, but a higher percentage of subjects in the shared decision-making group (70\%) than in the clinician decision-making group $(61 \%)$ had an increase of $>0.5$ point in the mini-AQLQ. At both the 1-y and 2-y follow-ups, subjects in the shared decision-making group had used less short-acting $\beta_{2}$ agonists than those in the clinician decision-making group (6.5 vs 7.1 and 4.7 vs 6.0 canisters, respectively), but the difference was not statistically significant. Both groups had fewer health-care utilizations in the post-randomization year compared with the pre-randomization year, but no significant difference was found between the 2 groups.

In 2012, Clark et al ${ }^{38}$ performed telephone interviews and reviewed medical records for 808 women with asthma and then repeated the data collection after 1 and $2 \mathrm{y}$ of follow-up (see Table 3). All subjects were asked if they had an asthma management plan developed together with their doctor describing how to adjust their medication with changing symptoms; if they took their prescribed medication usually, sometimes, or rarely; and if they were prescribed oral steroids. At baseline, those with a negotiated treatment plan were prescribed more medication and had a higher level of education. At follow-up, the odds ratio of adhering to ICS usually or sometimes with a negotiated plan was 2.4 compared without such a plan. A total of 41 women with a treatment plan used oral steroids at baseline; at follow-up, 23 of these women $(56 \%)$ were no longer on oral steroids. In comparison, 8 of 18 subjects (44\%) without a treatment plan had stopped oral steroids at follow-up. However, there were no differences in the number of hospitalizations, emergency department visits, or unscheduled physician visits. Women with a negotiated treatment plan were estimated to have $17 \%$ more days and $31 \%$ more nights without symptoms than those without such a plan, which suggests a more direct approach to 


\section{Asthma And AdHerence to InHaled Corticosteroids}

asthma treatment by physicians in more symptomatic patients.

Over a 6-month period, Gamble et $\mathrm{al}^{39}$ assessed ICS prescription fills for 239 subjects from the Northern Ireland Regional Difficult Asthma Service and defined nonadherence as $<50 \%$ of prescriptions filled (see Table 3 ). Demographics, lung function, oral steroid use, admissions, and quality-of-life data were obtained from the subjects' medical records. In phase 1, the non-adherent subjects ( 83 of 239) were confronted with their poor adherence and provided with a personal management plan. Following this intervention, $37 \%$ of the non-adherent subjects had an improvement in adherence at the second screening visit after 9 months, and these subjects were followed up for 6 months with regard to adherence and asthma outcome. The remaining $63 \%$ of the initial non-adherent subjects, together with 11 subjects who were adherent at baseline but not at the second screening, all received standard asthma care and another concordance discussion. In a pilot study, a total of 20 of these subjects were then randomized to either standard care (control group, $n=11$ ) or up to 8 visits during a 12-week period with a specialist respiratory nurse with basic psychotherapy training (intervention group, $n=9$ ). These visits addressed the subjects' individual reasons for non-adherence in a non-confrontational way, trying to promote self-motivation and resolve ambivalence about medication use. Of those initially non-adherent but adherent after the first concordance discussion, 90\% remained adherent at the third screening (15 months after the baseline screening). The daily dose of ICS and number of rescue courses of oral prednisolone were both significantly lower, and a reduction in the maintenance dose of prednisolone was also observed, although it was not statistically significant. In line with this, a reduction in hospital admissions due to exacerbations and an increase in $\mathrm{FEV}_{1}$ were also observed. In phase 2, 2 subjects in the intervention group failed to show up, but the remaining 7 subjects had an improvement in adherence from 38 to $62 \%$, whereas adherence decreased from 32 to $29 \%$ in the control group. The number of subjects in the group filling $>50 \%$ of their ICS prescriptions also increased (4/7 vs $1 / 11$ in the control group). At the third screening, the maintenance dose of oral prednisolone was significantly reduced in the intervention group (15.0 and $9.4 \mathrm{mg}$, respectively), whereas the control group received a higher dose of prednisolone on average.

Ulrik et $\mathrm{al}^{40}$ conducted a 26 -week study assessing the effects of compliance enhancement training on ICS adherence in 361 adults with asthma (see Table 3). After 2 weeks run-in, in which the subjects continued on their usual medication, they were switched to a fixed combination of salmeterol/fluticasone at 50/250 $\mu \mathrm{g}$ twice daily for a 12 -week period. Their adherence to ICS was estimated by counting the remaining number of doses in the returned inhalers.
Every day, the subjects monitored their percent-predicted $\mathrm{FEV}_{1}, \mathrm{PEF}$, symptoms, rescue medication use, nighttime awakenings, exacerbations, change in medication due to side effects, unscheduled doctor visits, and quality of life (AQLQ). Based on these parameters, the proportion of subjects with total control for at least 7 of 8 consecutive weeks was calculated. A total of $24.1 \%$ achieved this primary end point after treatment period 1 . The remaining 274 subjects continued with an unchanged dose of controller medication and were randomized to the intervention group $(n=140)$ or the control group. The intervention consisted of 3 sessions of $\sim 60$ min of compliance enhancement training, including education on asthma pathophysiology, living with asthma, the subjects' treatment expectations, correct use of inhalers, and help in remembering their controller therapy. More than $90 \%$ of the subjects in the intervention group participated in each session. Only $8.2 \%$ of the subjects achieved total control for at least 7 of 8 consecutive weeks, with no statistically significant difference found between groups. However, although not statistically significant, subjects with mild asthma were more likely to achieve total control compared with those with moderate asthma. A statistically significant improvement in mean weekly PEF, $\mathrm{FEV}_{1}$, and quality of life, as well as a reduction in days with symptoms and rescue medication, was found, but with no significant difference between the groups.

In other chronic diseases, simplifying dosing regimens has resulted in better adherence to medication, ${ }^{43-45}$ which has also been shown in clinical trials of ICS therapy for asthma. ${ }^{46}$ Wells et $\mathrm{al}^{47}$ assessed whether better adherence to a simpler dosing regimen is also found in a real-life setting or whether it is a direct effect of participating in a clinical trial. They compared prescription information with pharmacy claims for 1,302 asthma subjects for a 6-y period, with the end of follow-up being their last ICS prescription fill or a switch to fixed-combination ICS/longacting $\beta_{2}$ agonist therapy. Subjects were divided into either once-daily or twice-or-more daily regimens. For subjects with a change in therapy during the follow-up, the date of switching was counted as the last day of the first period and the first day of the last period. Adherence was $61 \%$ in the once-daily treatment group versus $41 \%$ in those subjects prescribed ICS more than once daily. The former group was also more likely to have an adherence of $>75 \%$ (41\% vs $17 \%)$. When assessing the changes in adherence for those who switched regimens, a once-daily prescription resulted in higher levels of adherence regardless of the initial dosing regimen (64\% vs $48 \%$ for those who were initially prescribed at least twice-daily therapy and $74 \%$ vs $48 \%$ for the initial once-daily group). Oncedaily ICS prescriptions were not associated with a statistically significant difference in incidence of severe asthma exacerbations. 
Based on the reviewed studies, no specific intervention has proven to be superior in successfully improving adherence to ICS, as well as for the overall well-being of subjects with asthma. However, some of the interventions led to improved quality of life, fewer symptoms, and better adherence, whereas others failed to prove any significant differences versus control groups. However, most of the interventions were very well received by the subjects, who expressed interest in continuing with the intervention and felt an improvement in their asthma, even though this could not be objectively verified in general.

\section{Summary and Perspectives}

For the present review, 19 studies met the inclusion criteria by focusing on the level of adherence to ICS, the effect of the level of adherence on asthma symptoms or outcomes, and possible interventions to improve ICS adherence. Some of the studies focused on more than one of these aspects.

Nine studies focused on the level of adherence to ICS. The mean adherence was found to be between 22 and $63 \%$, thus not nearly approaching the $80 \%$ cutoff of good adherence. Factors associated with the lowest level of adherence were age (younger subjects had poorer adherence than older subjects), being African-American, having a low level of education ( $<12 \mathrm{y}$ of formal education), mild asthma, and poor communication with health-care providers.

In the 6 studies focusing on the effect of poor adherence on asthma symptoms and outcomes, good adherence led to an increase in $\mathrm{FEV}_{1}$, a lower sputum eosinophil counts, fewer asthma-related hospitalizations and courses of oral steroids, and a decrease in mortality rate. It was estimated that as many as $24 \%$ of asthma exacerbations and $60 \%$ of asthma-related hospitalizations could be avoided with increased ICS adherence.

Most studies found increased adherence with a focused intervention, regardless of the type of intervention. Some found that the increased adherence was associated with improved quality of life, fewer symptoms, higher $\mathrm{FEV}_{1}$, and fewer courses of oral steroids, whereas others did not report any differences between intervention and control groups, and one study reported more symptoms in the intervention group.

Adherence to a prescribed treatment is essential for it to have an effect, and non-adherence can occur in several ways. In addition to agreeing to take the medication (acceptance), the patient also has to follow the treatment as prescribed (observance) and keep following it over time (persistence). ${ }^{48}$ Non-adherence can be not filling the prescription, not using the medication when filled (intentionally or due to forgetfulness) using the medication too often or too seldom, taking too much or not enough, or using it the wrong way, intentionally or non-intentionally. It can be due to practical aspects, such as low income or low health literacy, as in not having the "capacity to obtain, process and understand basic health information and services needed to make appropriate health decisions", ${ }^{49}$ or can be due to beliefs about the illness (eg, patients believe that they have asthma only when they have symptoms or that their doctor can cure asthma) or the treatment (benefits, necessity, concerns). ${ }^{50}$

In a review by Cochrane et al, ${ }^{51}$ subjects were found to take their ICS as prescribed only $20-73 \%$ of the time. The big span in ICS adherence rates could be caused by actual variations in adherence or could reflect different ways of measuring adherence. Several studies have shown the level of ICS adherence to be dependent on the method of measuring, ${ }^{52-54}$ but even when including only studies using $\mathrm{CMA} /$ medical possession ratio as a measure of ICS adherence, the average adherence has been shown to range from $22 \%$ to $50 \% .{ }^{19} \mathrm{CMA}$ is considered to be reliable way of measuring ICS adherence, as it does not involve patient self-reporting, which leads to overestimated adherence, ${ }^{52}$ although clearly communicating a no-blame attitude highly improves the accuracy of self-reporting. ${ }^{55}$ One of the major problems with assessing adherence as CMA is that we have no way of knowing if the patients take their medication after filling their prescriptions or if they use the correct inhalation techniques, and thus, actual adherence might be even lower than that calculated.

Another debatable point is the cutoff between good and poor adherence. The most commonly used value is $80 \%,{ }^{20,56}$ Lasmar et al ${ }^{57}$ showed $80 \%$ to be the threshold between controlled and uncontrolled asthma, whereas Schroeder et $\mathrm{al}^{58}$ argued that an arbitrary cutoff value is meaningless and should be replaced with a continuous measure of adherence. In the articles included in this review, the cutoff value varied between 50 and $80 \%$. However, the cutoff value did not seem to influence how many subjects were considered to have poor adherence in these studies.

Despite various attempts at intervention, adherence to ICS remains low. Most studies reported increased adherence in both control and intervention groups. This could be due to the enrollment effect ${ }^{59}$ or because the subjects were followed more closely and therefore paid more attention to taking their ICS. Several studies found improved symptoms, quality of life, and lung function, but all improvements were small and might have returned to normal values with the decreased focus on adherence after the studies ended.

Several studies have shown that poor adherence to ICS leads to negative outcomes. ${ }^{60,61}$ In only one of the studies included this review, an improvement in adherence did not lead to improved symptoms but still lead to a higher $\mathrm{FEV}_{1}$ and lower sputum eosinophil count. ${ }^{18}$ This shows that patients should strive to improve their ICS adherence not 


\section{Asthma And Adherence to Inhaled Corticosteroids}

only to meet a certain clinical standard but also because it results in fewer symptoms and better lung function.

There are several paths to take in the future to achieve optimal or at least better adherence to ICS and thus improve asthma control. First, it is important to measure the actual level of non-adherence. To do this, a reliable, objective, easy, and inexpensive way of measuring adherence should be developed. One possibility may be using electronic monitoring devices, ${ }^{62}$ as done by Patel et $\mathrm{al}^{63}$ in a real-world randomized controlled trial. Their study showed that using a Smartinhaler Tracker, an electronic monitor for metered-dose inhalers that records date, time, and number of actuations, was a reliable measure of metered-dose inhaler use. Furthermore, Van Sickle et al ${ }^{64}$ have shown that an electronic medication sensor attached to a rescue bronchodilator inhaler, weekly e-mail reports, and access to online charts summarizing remote monitoring of inhaled bronchodilator frequency can improve asthma control. In line with this, in an ongoing trial, Vasbinder et al ${ }^{65}$ are investigating the effects on adherence of a real-time medication-monitoring system, which registers time and date of ICS doses, combined with tailored text messages via a mobile telephone network when an ICS dose is missed.

Methods aiming to improve adherence to ICS should ideally also clearly distinguish between non-adherent and treatment-resistant patients to avoid trials with new expensive medications in the former and futile attempts with higher doses of ICS in the latter. In addition, patients' reasons for non-adherence should be explored, as there are many different forms of non-adherence. Finding out why a patient does not adhere to the prescribed treatment regimen will give an indication of which interventions would possibly be the most effective in each individual case. Finally, developing and testing different interventions targeting the different reasons for non-adherence and making an effort to individualize the interventions, whether technical, behavioral, or educational, should be a high priority, instead of focusing on developing only new and more effective controller medications for asthma.

\section{REFERENCES}

1. Masoli M, Fabian D, Holt S, Beasley R, Global Initiative for Asthma (GINA) Program. The global burden of asthma: executive summary of the GINA Dissemination Committee report. Allergy 2004;59(5): 469-478.

2. Accordini S, Corsico AG, Braggion M, Gerbase MW, Gislason D, Gulsvik A, et al. The cost of persistent asthma in Europe: an international population-based study in adults. Int Arch Allergy Immunol 2013;160(1):93-101.

3. Backer V, Ulrik CS, Hansen KK, Laursen EM, Dirksen A, BachMortensen N. Atopy and bronchial responsiveness in random population sample of 527 children and adolescents. Ann Allergy 1992; 69(2):116-122.
4. Eder W, Ege MJ, von Mutius E. The asthma epidemic. N Engl J Med 2006;355(21):2226-2235.

5. Bateman ED, Hurd SS, Barnes PJ, Bousquet J, Drazen JM, FitzGerald M, et al. Global strategy for asthma management and prevention: GINA executive summary. Eur Respir J 2008;31(1):143-178.

6. Blais L, Suissa S, Boivin JF, Ernst P. First treatment with inhaled corticosteroids and the prevention of admissions to hospital for asthma. Thorax 1998;53(12):1025-1029.

7. Haahtela T, Järvinen M, Kava T, Kiviranta K, Koskinen S, Lehtonen $\mathrm{K}$, et al. Comparison of a $\beta_{2}$-agonist, terbutaline, with an inhaled corticosteroid, budesonide, in newly detected asthma. N Engl J Med 1991;325(6):388-392.

8. Pauwels RA, Pedersen S, Busse WW, Tan WC, Chen YZ, Ohlsson $\mathrm{SV}$, et al. Early intervention with budesonide in mild persistent asthma: a randomised, double-blind trial. Lancet 2003;361(9363):10711076.

9. Barnes PJ, Woolcock AJ. Difficult asthma. Eur Respir J 1998;12(5): 1209-1218.

10. Davidsen JR. Drug utilization and asthma control among young Danish adults with asthma. Analyses of trends and determinants. Dan Med J 2012;59(8):B4501.

11. Kandane-Rathnayake RK, Matheson MC, Simpson JA, Tang ML, Johns DP, Meszaros D, et al. Adherence to asthma management guidelines by middle-aged adults with current asthma. Thorax 2009; 64(12):1025-1031.

12. Krishnan JA, Riekert KA, McCoy JV, Stewart DY, Schmidt S, Chanmugam A, et al. Corticosteroid use after hospital discharge among high-risk adults with asthma. Am J Respir Crit Care Med 2004; 170(12):1281-1285.

13. Piecoro LT, Potoski M, Talbert JC, Doherty DE. Asthma prevalence, cost, and adherence with expert guidelines on the utilization of health care services and costs in a state Medicaid population. Health Serv Res 2001;36(2):357-371.

14. Tan R, Corren J. Omalizumab in the treatment of asthma. Expert Rev Respir Med 2011;5(6):747-756.

15. Liberati A, Altman DG, Tetzlaff J, Mulrow C, Gøtzsche PC, Ioannidis JP, et al. The PRISMA statement for reporting systematic reviews and meta-analyses of studies that evaluate health care interventions: explanation and elaboration. J Clin Epidemiol 2009;62(10): e1-e34.

16. Moher D, Liberati A, Tetzlaff J, Altman DG, PRISMA Group. Preferred reporting items for systematic reviews and meta-analyses: the PRISMA statement. BMJ 2009;339:b2535.

17. Williams LK, Joseph CL, Peterson EL, Wells K, Wang M, Chowdhry VK, et al. Patients with asthma who do not fill their inhaled corticosteroids: a study of primary nonadherence. J Allergy Clin Immunol 2007;120(5):1153-1159.

18. Williams LK, Peterson EL, Wells K, Ahmedani BK, Kumar R, Burchard EG, et al. Quantifying the proportion of severe asthma exacerbations attributable to inhaled corticosteroid nonadherence. J Allergy Clin Immunol 2011;128(6):1185.e2-1191.e2.

19. Williams LK, Pladevall M, Xi H, Peterson EL, Joseph C, Lafata JE, et al. Relationship between adherence to inhaled corticosteroids and poor outcomes among adults with asthma. J Allergy Clin Immunol 2004;114(6):1288-1293.

20. Murphy AC, Proeschal A, Brightling CE, Wardlaw AJ, Pavord I, Bradding P, Green RH. The relationship between clinical outcomes and medication adherence in difficult-to-control asthma. Thorax 2012; 67(8):751-753.

21. Gamble J, Stevenson M, McClean E, Heaney LG. The prevalence of nonadherence in difficult asthma. Am J Respir Crit Care Med 2009; 180(9):817-822. 


\section{Asthma And AdHerence to InHALEd CoRTicosteroids}

22. Bender BG, Pedan A, Varasteh LT. Adherence and persistence with fluticasone propionate/salmeterol combination therapy. J Allergy Clin Immunol 2006;118(4):899-904.

23. Hwang EK, Jin HJ, Nam YH, Shin YS, Ye YM, Nahm DH, Park HS. The predictors of poorly controlled asthma in elderly. Allergy Asthma Immunol Res 2012;4(5):270-276.

24. Ulrik CS, Søes-Petersen U, Backer V, Lange P, Harving H, Plaschke P. Disease variability in asthma: how do the patients respond?-and why? J Asthma 2008;45(6):507-511.

25. Apter AJ, Reisine ST, Affleck G, Barrows E, ZuWallack RL. Adherence with twice-daily dosing of inhaled steroids. Socioeconomic and health-belief differences. Am J Respir Crit Care Med 1998; 157(6 Pt 1):1810-1817.

26. Suissa S, Ernst P, Kezouh A. Regular use of inhaled corticosteroids and the long term prevention of hospitalisation for asthma. Thorax 2002;57(10):880-884.

27. Suissa S, Ernst P, Benayoun S, Baltzan M, Cai B. Low-dose inhaled corticosteroids and the prevention of death from asthma. N Engl J Med 2000;343(5):332-336.

28. Bateman ED, Boushey HA, Bousquet J, Busse WW, Clark TJ, Pauwels RA, et al. Can guideline-defined asthma control be achieved? The Gaining Optimal Asthma Control study. Am J Respir Crit Care Med 2004;170(8):836-844.

29. Juniper EF, O'Byrne PM, Guyatt GH, Ferrie PJ, King DR. Development and validation of a questionnaire to measure asthma control. Eur Respir J 1999;14(4):902-907.

30. van Dixhoorn J, Duivenvoorden HJ. Efficacy of Nijmegen Questionnaire in recognition of the hyperventilation syndrome. J Psychosom Res 1985;29(2):199-206.

31. Snaith RP. The Hospital Anxiety And Depression Scale. Health Qual Life Outcomes 2003;1:29.

32. Jin Y, Hu D, Peterson EL, Eng C, Levin AM, Wells K, et al. Dualspecificity phosphatase 1 as a pharmacogenetic modifier of inhaled steroid response among asthmatic patients. J Allergy Clin Immunol 2010;126(3):618.e2-625.e2.

33. Bateman ED, Frith LF, Braunstein GL. Achieving guideline-based asthma control: does the patient benefit? Eur Respir J 2002;20(3): 588-595.

34. Rasmussen LM, Phanareth K, Nolte H, Backer V. Internet-based monitoring of asthma: a long-term, randomized clinical study of 300 asthmatic subjects. J Allergy Clin Immunol 2005;115(6):1137-1142.

35. Araújo L, Jacinto T, Moreira A, Castel-Branco MG, Delgado L, Costa-Pereira A, Fonseca J. Clinical efficacy of web-based versus standard asthma self-management. J Invest Allergog Clin Immunol 2012;22(1):28-34.

36. Vollmer WM, Feldstein A, Smith DH, Dubanoski JP, Waterbury A, Schneider JL, et al. Use of health information technology to improve medication adherence. Am J Manag Care 2011;17(12 Spec No): SP79-SP87.

37. Wilson SR, Strub P, Buist AS, Knowles SB, Lavori PW, Lapidus J, et al. Shared treatment decision making improves adherence and outcomes in poorly controlled asthma. Am J Respir Crit Care Med 2010;181(6):566-577.

38. Clark NM, Ko YA, Gong ZM, Johnson TR. Outcomes associated with a negotiated asthma treatment plan. Chron Respir Dis 2012; 9(3):175-182.

39. Gamble J, Stevenson M, Heaney LG. A study of a multi-level intervention to improve non-adherence in difficult to control asthma. Respir Med 2011;105(9):1308-1315.

40. Ulrik CS, Claudius BK, Tamm M, Harving H, Siersted HC, Backer $\mathrm{V}$, et al. Effect of asthma compliance enhancement training on asthma control in patients on combination therapy with salmeterol/fluticasone propionate: a randomised controlled trial. Clin Respir J 2009; 3(3):161-168.
41. Winder JA, Nash K, Brunn JW. Validation of a life quality (LQ) test for asthma. Ann Allergy Asthma Immunol 2000;85(6 Pt 1): 467-472.

42. Dweik RA, Boggs PB, Erzurum SC, Irvin CG, Leigh MW, Lundberg JO, et al. An official ATS clinical practice guideline: interpretation of exhaled nitric oxide levels $\left(\mathrm{F}_{\mathrm{ENO}}\right.$ ) for clinical applications. Am J Respir Crit Care Med 2011;184(5):602-615.

43. Emkey RD, Ettinger M. Improving compliance and persistence with bisphosphonate therapy for osteoporosis. Am J Med 2006;119(4 Suppl 1):S18-S24

44. Eisen SA, Miller DK, Woodward RS, Spitznagel E, Przybeck TR. The effect of prescribed daily dose frequency on patient medication compliance. Arch Int Med 1990;150(9):1881-1884.

45. Glynn L, Fahey T. Cardiovascular medication: improving adherence. Clin Evid 2009;0220.

46. Price D, Robertson A, Bullen K, Rand C, Horne R, Staudinger H. Improved adherence with once-daily versus twice-daily dosing of mometasone furoate administered via a dry powder inhaler: a randomized open-label study. BMC Pulm Med 2010;10:1.

47. Wells KE, Peterson EL, Ahmedani BK, Williams LK. Real-world effects of once vs greater daily inhaled corticosteroid dosing on medication adherence. Ann Allergy Asthma Immunol 2013;111(3): 216-220.

48. Boulet LP, Vervloet D, Magar Y, Foster JM. Adherence: the goal to control asthma. Clin Chest Med 2012;33(3):405-417.

49. Apter AJ, Wan F, Reisine S, Bender B, Rand C, Bogen DK, et al. The association of health literacy with adherence and outcomes in moderate-severe asthma. J Allergy Clin Immunol 2013;132(2):321327.

50. Sofianou A, Martynenko M, Wolf MS, Wisnivesky JP, Krauskopf $\mathrm{K}$, Wilson EA, et al. Asthma beliefs are associated with medication adherence in older asthmatics. J Gen Intern Med 2013;28(1): 67-73.

51. Cochrane MG, Bala MV, Downs KE, Mauskopf J, Ben-Joseph RH. Inhaled corticosteroids for asthma therapy: patient compliance, devices, and inhalation technique. Chest 2000;117(2):542-550.

52. Patel M, Perrin K, Pritchard A, Williams M, Wijesinghe M, Weatherall M, Beasley R. Accuracy of patient self-report as a measure of inhaled asthma medication use. Respirology 2013;18(3):546-552.

53. Rand CS, Wise RA, Nides M, Simmons MS, Bleecker ER, Kusek $\mathrm{JW}$, et al. Metered-dose inhaler adherence in a clinical trial. Am Rev Respir Dis 1992;146(6):1559-1564.

54. Braunstein GL, Trinquet G, Harper AE. Compliance with nedocromil sodium and a nedocromil sodium/salbutamol combination. Compliance Working Group. Eur Respir J 1996;9(5):893-898.

55. Clatworthy J, Price D, Ryan D, Haughney J, Horne R. The value of self-report assessment of adherence, rhinitis and smoking in relation to asthma control. Prim Care Respir J 2009;18(4):300-305.

56. Clerisme-Beaty EM, Bartlett SJ, Teague WG, Lima J, Irvin CG, Cohen R, et al. The Madison Avenue effect: how drug presentation style influences adherence and outcome in patients with asthma. J Allergy Clin Immunol 2011;127(2):406-411.

57. Lasmar L, Camargos P, Champs NS, Fonseca MT, Fontes MJ, Ibiapina $\mathrm{C}$, et al. Adherence rate to inhaled corticosteroids and their impact on asthma control. Allergy 2009;64(5):784-789.

58. Schroeder K, Fahey T, Ebrahim S, Peters TJ. Adherence to longterm therapies: recent WHO report provides some answers but poses even more questions. J Clin Epidemiol 2004;57(1):2-3.

59. Rand CS, Nides M, Cowles MK, Wise RA, Connett J. Long-term metered-dose inhaler adherence in a clinical trial. The Lung Health Study Research Group. Am J Respir Crit Care Med 1995;152(2): 580-588. 


\section{Asthma And AdHerence to InHALEd CoRTicosteroids}

60. Bousquet J, Mantzouranis E, Cruz AA, Aït-Khaled N, Baena-Cagnani CE, Bleecker ER, et al. Uniform definition of asthma severity, control, and exacerbations: document presented for the World Health Organization Consultation on Severe Asthma. J Allergy Clin Immunol 2010;126(5):926-938.

61. Neffen H, Fritscher C, Schacht FC, Levy G, Chiarella P, Soriano JB, et al. Asthma control in Latin America: the Asthma Insights and Reality in Latin America (AIRLA) survey. Rev Panam Salud Publica 2005;17(3):191-197.

62. Patel M, Pilcher J, Chan A, Perrin K, Black P, Beasley R. Six-month in vitro validation of a metered-dose inhaler electronic monitoring device: implications for asthma clinical trial use. J Allergy Clin Immunol 2012;130(6):1420-1422.
63. Patel M, Pilcher J, Travers J, Perrin K, Shaw D, Black P, et al. Use of metered-dose inhaler electronic monitoring in a real-world asthma randomized controlled trial. J Allergy Clin Immunol Pract 2013; 1(1):83-91.

64. Van Sickle D, Magzamen S, Truelove S, Morrison T. Remote monitoring of inhaled bronchodilator use and weekly feedback about asthma management: an open-group, short-term pilot study of the impact on asthma control. PLoS ONE 2013;8(2):e55335.

65. Vasbinder EC, Janssens HM, Rutten-van Molken MP, van Dijk L, de Winter BC, de Groot RC, et al. e-Monitoring of Asthma Therapy to Improve Compliance in children using a real-time medication monitoring system (RTMM): the e-MATIC study protocol. BMC Med Informatics Decision Making 2013;13:38 